Revta brasil. Bot., São Paulo, V.24, n.3, p.273-281, set. 2001

\title{
Estrutura de uma comunidade arbustiva da restinga de Barra de Maricá - RJ
}

\author{
MIRIAM CRISTINA ALVAREZ PEREIRA ${ }^{1,4}$, DOROTHY SUE DUNN DE ARAUJO ${ }^{2} \mathrm{e}$ \\ OBERDAN JOSÉ PEREIRA ${ }^{3}$
}

(recebido: 24 de maio de 2000; aceito: 2 de maio de 2001)

\begin{abstract}
The structure of shrubby coastal-plain vegetation at Barra de Maricá, Rio de Janeiro - Brazil). The structure of dense shrubby vegetation growing on the beach ridges at Barra de Maricá, Brazil (22 $53^{\circ} \mathrm{S}$ and $\left.42^{\circ} 50^{\prime} \mathrm{W}\right)$ was studied using the line intercept method; 398 woody plants over $50 \mathrm{~cm}$ tall were sampled in $350 \mathrm{~m}$ for a total of 42 species. The most important families of this plant community are Myrtaceae (nine species) and Leguminosae (five species). Myrtaceae was first in number of individuals and importance value. Clusia lanceolata Cambess. (Guttiferae), Maytenus obtusifolia Mart. (Celastraceae), Myrrhinium atropurpureum Schott (Myrtaceae) and the genus Guapira (Nyctaginaceae; three species) had the highest species importance values. Species diversity $\left(\mathrm{H}^{\prime}=2.84\right.$ nats/ind.) is similar to that of other shrubby coastal plain communities in southeastern Brazil, but there are a greater number of rare species $(38 \%)$. This community was identified as a Myrtaceae "thicket".
\end{abstract}

RESUMO - (Estrutura de uma comunidade arbustiva da restinga de Barra de Maricá - RJ). Uma comunidade arbustiva fechada, localizada no cordão arenoso interno da restinga de Barra de Maricá $\left(22^{\circ} 53^{\prime} \mathrm{S}\right.$ e $\left.42^{\circ} 50^{\prime} \mathrm{W}\right)$ foi descrita utilizando-se o método de intercepção por linha. Foram amostrados, em $350 \mathrm{~m}$ de linha, 398 indivíduos lenhosos com altura superior a $50 \mathrm{~cm}$, distribuídos em 42 espécies. As famílias mais importantes floristicamente foram Myrtaceae (nove espécies) e Leguminosae (cinco espécies). Quanto à estrutura da vegetação, Myrtaceae apresentou o maior número de indivíduos e o maior valor de importância. As espécies que obtiveram os maiores valores de importância foram: Clusia lanceolata Cambess. (Guttiferae), Maytenus obtusifolia Mart. (Celastraceae), Myrrhinium atropurpureum Schott (Myrtaceae) e o gênero Guapira (Nyctaginaceae), representado por três espécies. O percentual de espécies raras (38\%) é superior e a diversidade específica $\left(\mathrm{H}^{\prime}=2,84\right.$ nats/ind.) semelhante aos valores observados em outras comunidades de restinga da região Sudeste. A comunidade analisada foi identificada como arbustiva fechada de Myrtaceae.

Key words - Coastal vegetation structure, line intercept method, southeastern Brazil

\section{Introdução}

Nas restingas do estado do Rio de Janeiro, as comunidades praianas têm sido o objeto da maioria dos estudos ecológicos, já as comunidades arbustivas abertas e as arbóreas, mais afastadas da praia, foram consideradas com menor ênfase. Nenhum estudo descritivo foi realizado, até o momento, nas comunidades arbustivas fechadas, criando uma lacuna nos dados disponíveis sobre a vegetação de restinga, o que tem dificultado o estabelecimento de uma nomenclatura unificada para as comunidades de restinga no Brasil.

1. Herbarium Bradeanum, Caixa Postal 15005, 20031-970 Rio de Janeiro, RJ, Brasil.

2. Universidade Federal do Rio de Janeiro, IB - CCS, Departamento de Ecologia, Caixa Postal 68020, Ilha do Fundão, 21941-590 Rio de Janeiro, RJ, Brasil.

3. Universidade Federal do Espírito Santo, Setor Botânica, Av. Fernando Ferrari s/n, Campus Goiabeiras, 29060-900 Vitória, ES, Brasil.

4. Autor para correspondência: miriamcap@ig.com.br
A importância dos estudos descritivos sobre vegetação de restinga para a preservação ambiental e manejo de unidades de conservação reside no fornecimento de dados sobre a dinâmica de comunidades. Essas pesquisas procuram, ainda, facilitar a escolha de espécies cujas populações mereçam estudos mais detalhados, objetivando a preservação de espécies raras e o aumento de conhecimento sobre estratégias bem sucedidas na colonização de ambientes com solos pobres, como os de restinga.

Estudos fitossociológicos realizados nas restingas do estado do Rio de Janeiro e enfocando comunidades arbustivas e arbóreas foram desenvolvidos por Araujo \& Peixoto (1977), Henriques et al. (1986), Silva (1991), Ribas (1992), Ribas et al. (1993), Sá (1996), Montezuma (1997), Zaluar (1997) e Assumpção \& Nascimento (1998, 2000).

Este trabalho tem por objetivos descrever a estrutura da vegetação arbustiva fechada do cordão arenoso interno da restinga de Barra de Maricá, comparar os resultados obtidos com os de outros 
estudos realizados em comunidades arbustivas e arbóreas de restinga, identificar a comunidade estudada utilizando a classificação proposta por Araujo \& Henriques (1984) colaborando com a discussão sobre a nomenclatura utilizada para designar as formações vegetais de restinga, e ainda, contribuir para o entendimento da dinâmica de moitas, pois não existem dados disponíveis sobre esse tipo de comunidade para o Estado do Rio de Janeiro.

\section{Material e métodos}

Área de estudo - A Área de Proteção Ambiental (APA) de Maricá foi criada através do Decreto Estadual no 7.230 de 23 de abril de 1984, estando localizada a leste da cidade do Rio de Janeiro, a aproximadamente $50 \mathrm{~km}$, entre as coordenadas $22^{\circ} 52^{\prime}$ a $22^{\circ} 54^{\prime} \mathrm{S}$ e $42^{\circ} 48^{\prime}$ a $42^{\circ} 54^{\prime} \mathrm{W}$, com uma área total de $8,3 \mathrm{~km}^{2}$ (figura 1).

O clima da região de Maricá foi classificado por Nimer (1972) como tropical quente, superúmido, com subseca. Dados meteorológicos provêm do município de Niterói (Departamento Nacional de Meteorologia, período de 1931 a 1968), sendo a temperatura média anual $23,2^{\circ} \mathrm{C}$, a média das máximas do mês mais quente (fevereiro) $32,2^{\circ} \mathrm{C}$ e das mínimas do mês mais frio (julho) $15,1^{\circ} \mathrm{C}$. A precipitação média anual é de $1.230,8 \mathrm{~mm}$, com $69,2 \%$ ocorrendo de novembro a abril.

A restinga de Barra de Maricá apresenta dois cordões arenosos separados por uma depressão, onde ocorre um brejo de água doce originado pelo afloramento do lençol freático. Estes cordões resultaram de dois episódios da última transgressão marinha; o cordão interno foi formado entre 5.000 e 5.500 anos A.P. e o externo em torno de 3.500 anos A.P. (Perrin 1984). O perfil topográfico da área mostra diferenças de altura e largura entre os dois cordões (figura 2).

No local de estudo, encontram-se várias comunidades vegetais que acompanham a topografia do terreno (figura 2). A comunidade aqui estudada forma uma faixa estreita e contínua de vegetação, paralela à linha da costa, cobrindo a face do cordão arenoso interno voltada para o brejo, desde a faixa de transição com o brejo até a crista deste cordão (325-480 m). $\mathrm{Na}$ orla desta comunidade, próximo à faixa de transição brejocordão, a vegetação apresenta-se como um emaranhado de ervas e arbustos baixos (até $80 \mathrm{~cm}$ de altura), com cobertura quase contínua de gravatás (Neoregelia cruenta (Graham) L.B. Smith, Vriesea neoglutinosa Mez - Bromeliaceae). Em direção à crista do cordão, os arbustos aumentam em altura (até $3 \mathrm{~m}$ ), formando um ambiente sombreado, que é ocupado muito esparsamente por ervas umbrófilas (e.g. Neomarica northiana (Schneev.) Sprague - Iridaceae, Billbergia amoena (Lodd.) Lindl. - Bromeliaceae, Anthurium spp. - Araceae, Dichorisandra thrysiflora Mikan - Commelinaceae). As epífitas são raras, no entanto, é comum encontrar nas copas dos arbustos plantas trepadeiras, como Orthosia arenosa Decne. (Asclepiadaceae), Vanilla chamissonis Klotzsch (Orchidaceae), Mandevilla funiformis (Vell.) K. Schum. (Apocynaceae), Smilax rufescens Griseb. (Smilacaceae), Passiflora mucronata Lam. (Passifloraceae), entre outras.
Na face do cordão externo voltada para o continente, ocorre uma comunidade arbustiva fechada, cuja composição florística é pouco conhecida, mas que se aproxima, fisionomicamente, da arbustiva fechada de Myrtaceae ("Thicket" de Myrtaceae de Araujo \& Henriques 1984). No cordão interno, também na face voltada para o continente, encontra-se uma comunidade arbustiva em moitas dominada pelas mirtáceas (Silva 1991), mas que não se enquadra na classificação acima citada por ser uma formação descontínua.

Análise de comunidade - O perfil topográfico da área foi realizado segundo a metodologia de Garcia \& Piedade (1987). As medidas foram interrompidas na depressão intercordões às margens da lâmina d'água, no dia de tomada dos dados. O ponto inicial de referência foi estabelecido na zona entremarés e as alturas dos dois cordões arenosos estão relacionadas com este ponto.

Foram realizados, entre 1984 e 1988, os trabalhos de campo necessários, a diferenciação fisionômica das comunidades vegetais, o levantamento florístico e a análise da estrutura da comunidade, sendo os resultados deste último estudo e o perfil topográfico ora apresentados e discutidos.

A área amostrada encontra-se dividida em duas subáreas por uma estrada de terra que atravessa o cordão interno (figura 1). Em cada subárea, foi estabelecida uma linha base, paralela à costa, de $200 \mathrm{~m}$ de comprimento; perpendicularmente a cada uma destas, foram traçadas oito linhas, com extensão variando entre 20 e $30 \mathrm{~m}$ (16 linhas, totalizando $350 \mathrm{~m}$ divididos em intervalos de $10 \mathrm{~m}$ ), cortando transversalmente toda a comunidade em estudo. O ponto inicial de cada linha foi sorteado, utilizando-se tabela de números aleatórios.

Para análise quantitativa da estrutura da vegetação estudada, foi utilizado o método de intercepção por linha (Mueller-Dombois \& Ellenberg 1974). Foram amostrados os indivíduos lenhosos com altura superior a $50 \mathrm{~cm}$ e, para cada um destes, foram tomadas as seguintes medidas: a extensão do indivíduo interceptada pela projeção da linha e o maior diâmetro de copa perpendicular à linha. Pequenas interrupções nas copas dos arbustos interceptados foram ignoradas. O intercepto de copas muito irregulares que apresentaram interrupções maiores que $50 \mathrm{~cm}$ foi medido em partes e estas somadas.

Os parâmetros fitossociológicos, densidade linear, cobertura linear e freqüência absoluta e relativa $(\mathrm{k}=35) \mathrm{e}$, também, o valor de importância (VI) foram calculados através das fórmulas encontradas em Brower \& Zar (1984). O índice de cobertura linear é tratado no texto como dominância.

Para análise de similaridade florística entre as duas subáreas amostradas, foi utilizado o coeficiente de Sörensen $\left(\mathrm{C}_{\mathrm{S}}\right)$, por este ser amplamente utilizado na literatura, facilitando assim a comparação entre resultados de diferentes estudos. O coeficiente de Sörensen quantitativo $\left(\mathrm{C}_{\mathrm{N}}\right)$ foi calculado segundo Magurran (1988). A diversidade foi baseada na abundância das espécies, utilizando o índice de Shannon (Brower \& Zar 1984).

Foram consideradas como espécies raras aquelas representadas por apenas um indivíduo na amostragem (Martins 1991), e o índice de espécies raras a proporção destas em relação ao total de espécies amostradas.

A identificação dos espécimens estéreis foi realizada através da comparação com material fértil, anteriormente coletado na região e depositado no Herbário Alberto Castellanos - FEEMA (GUA). As espécies do gênero Guapira 


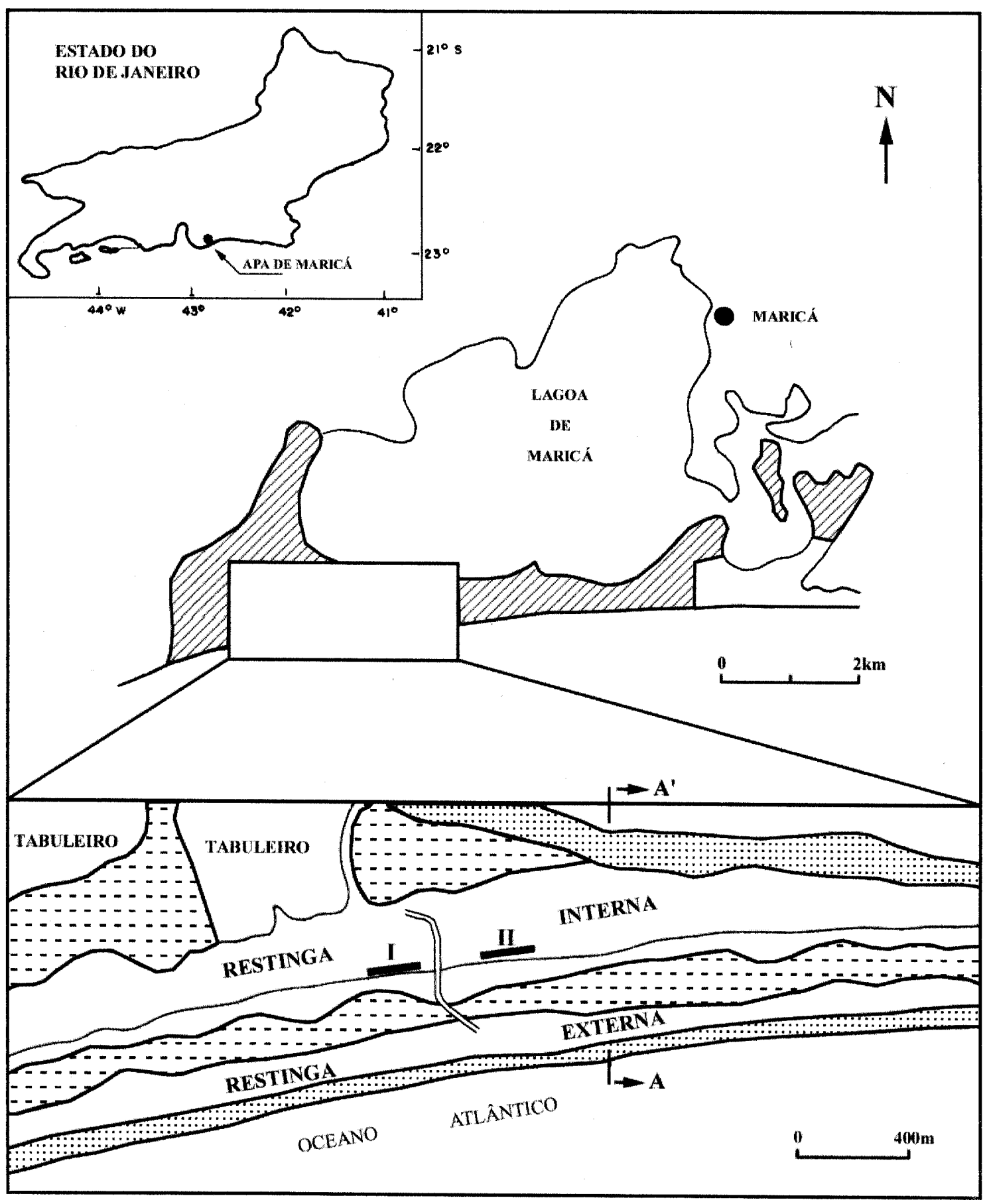

Figura 1. Localização da Área de Proteção Ambiental de Maricá (RJ). No detalhe são apresentadas as feições geomorfológicas

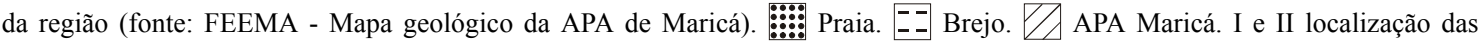
linhas base (subáreas I e II). A linha dupla entre estas faixas indica o trecho da estrada de barro que atravessa a área estudada. A transecção $\mathrm{A}-\mathrm{A}^{\prime}$ representa a posição do perfil topográfico (Ver figura 2). 


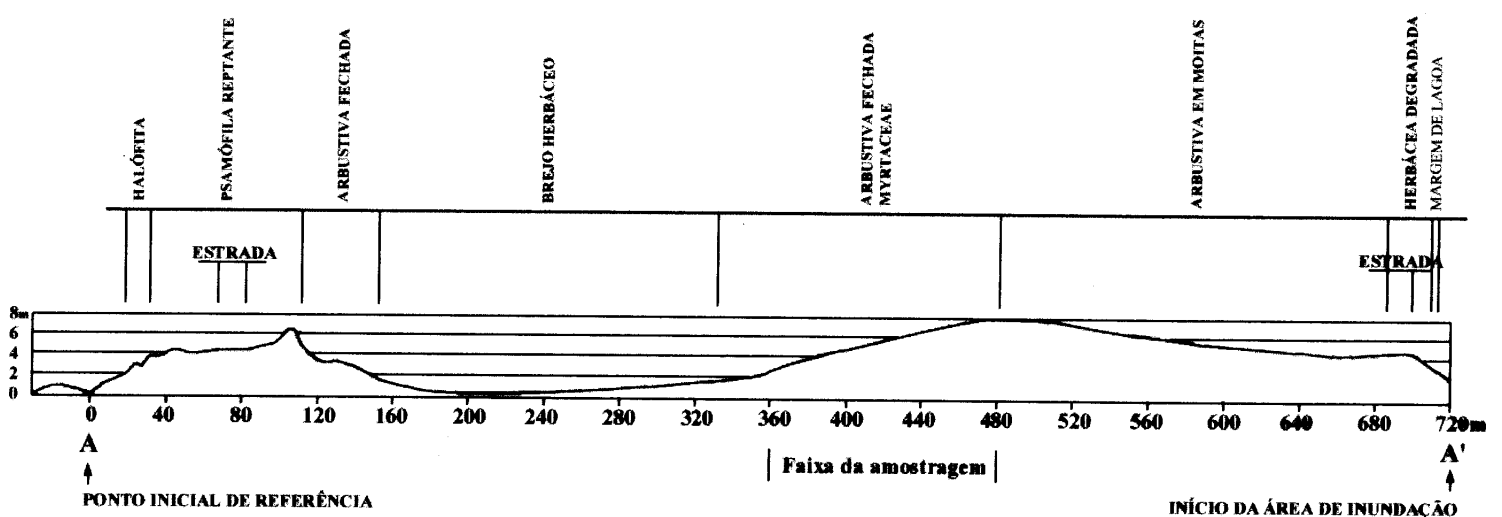

Figura 2. Perfil topográfico da restinga de Barra de Maricá, com a localização das comunidades vegetais. A localização deste perfil esta indicada na figura 1 pela transecção $\mathrm{A}-\mathrm{A}$ '.

(determinadas através de material fértil pelo especialista C.F.C. de Sá, nas linhas amostradas, como G. pernambucensis (Casar.) Lundell, G. opposita (Vell.) Reitz e Guapira sp. Nyctaginaceae) foram consideradas como um único táxon, devido à dificuldade de diferenciar no campo os indivíduos estéreis, que apresentam grande variabilidade nas estruturas vegetativas.

As famílias estão apresentadas de acordo com o Sistema de Classificação de Engler (1964). Os autores das espécies estão de acordo com Brummitt \& Powell (1992).

\section{Resultados e Discussão}

Foram amostrados, nos $350 \mathrm{~m}$ de linha, 42 espécies distribuídas em 35 gêneros de 22 famílias (tabela 1). As famílias mais ricas em espécies foram Myrtaceae (nove espécies), Leguminosae (cinco), Nyctaginaceae e Sapotaceae (três), Guttiferae, Lauraceae, Malpighiaceae e Rubiaceae (duas) e as demais, com uma espécie, representam $64 \%$ do total. A maioria dos gêneros $(83 \%)$ possui uma única espécie, enquanto Eugenia, Gomidesia, Myrcia, Ocotea e Pouteria possuem duas cada e Guapira três. O número de espécies está próximo aos registrados para outras comunidades arbustivas, contínuas e descontínuas, de restinga (35 a 43) nos estados do Rio de Janeiro e Espírito Santo (Fabris et al. 1990, Silva 1991, Montezuma 1997, Zaluar 1997).

Nas linhas de transecção, foram amostrados 398 indivíduos; a maior proporção destes (70\%) está concentrada nas três primeiras classes de diâmetro (figura 3). As famílias com maiores números de indivíduos foram Myrtaceae, com 99 (25\% do número total de indivíduos); Guttiferae - 72 (18\%),
Nyctaginaceae - $70(17,6 \%)$, Celastraceae - $38(9,5 \%)$ e Lauraceae - 23 (5,8\%). Estas totalizam $76 \%$ do número total de indivíduos.

As famílias com maiores VIs foram Myrtaceae $(63,6)$, Guttiferae $(56,7)$ e Nyctaginaceae $(52,7)$, somando $58 \%$ do total, sendo o restante dividido entre as demais 19.

Myrtaceae e Leguminosae são as duas famílias com maior riqueza florística nas restingas do Estado do Rio de Janeiro (Araujo 2000). Em função do grande número de espécies de Myrtaceae nas restingas, especificamente, entre 23 e $28 \%$ em comunidades

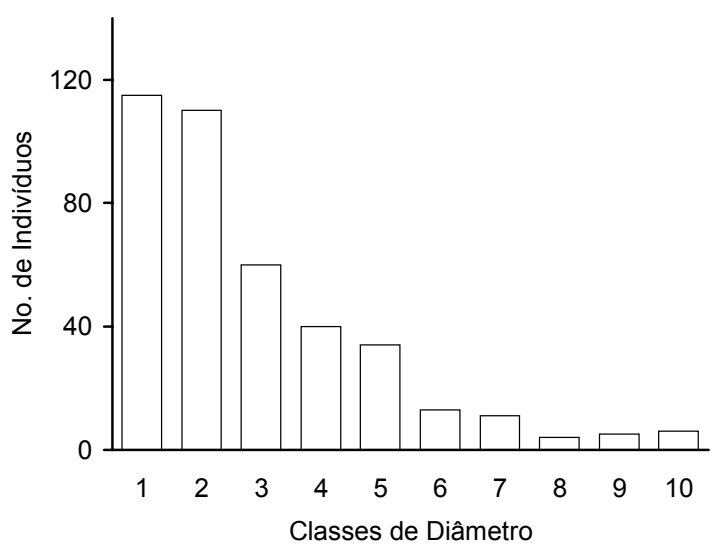

Figura 3. Distribuição em classes de diâmetro (m) de copa (maior diâmetro perpendicular à linha de intercepto) dos arbustos eretos da comunidade arbustiva fechada da restinga de Barra de Maricá. Classes de diâmetro (m): 1. 0,1-0,6; 2. $0,7-1,2$; 3. 1,3-1,8; 4. 1,9-2,4; 5. 2,5-3,0; 6. 3,1-3,6; 7. 3,74,$2 ; 8$. 4,3-4,8; 9. 4,9-5,4; 10. 5,5-6,0. 


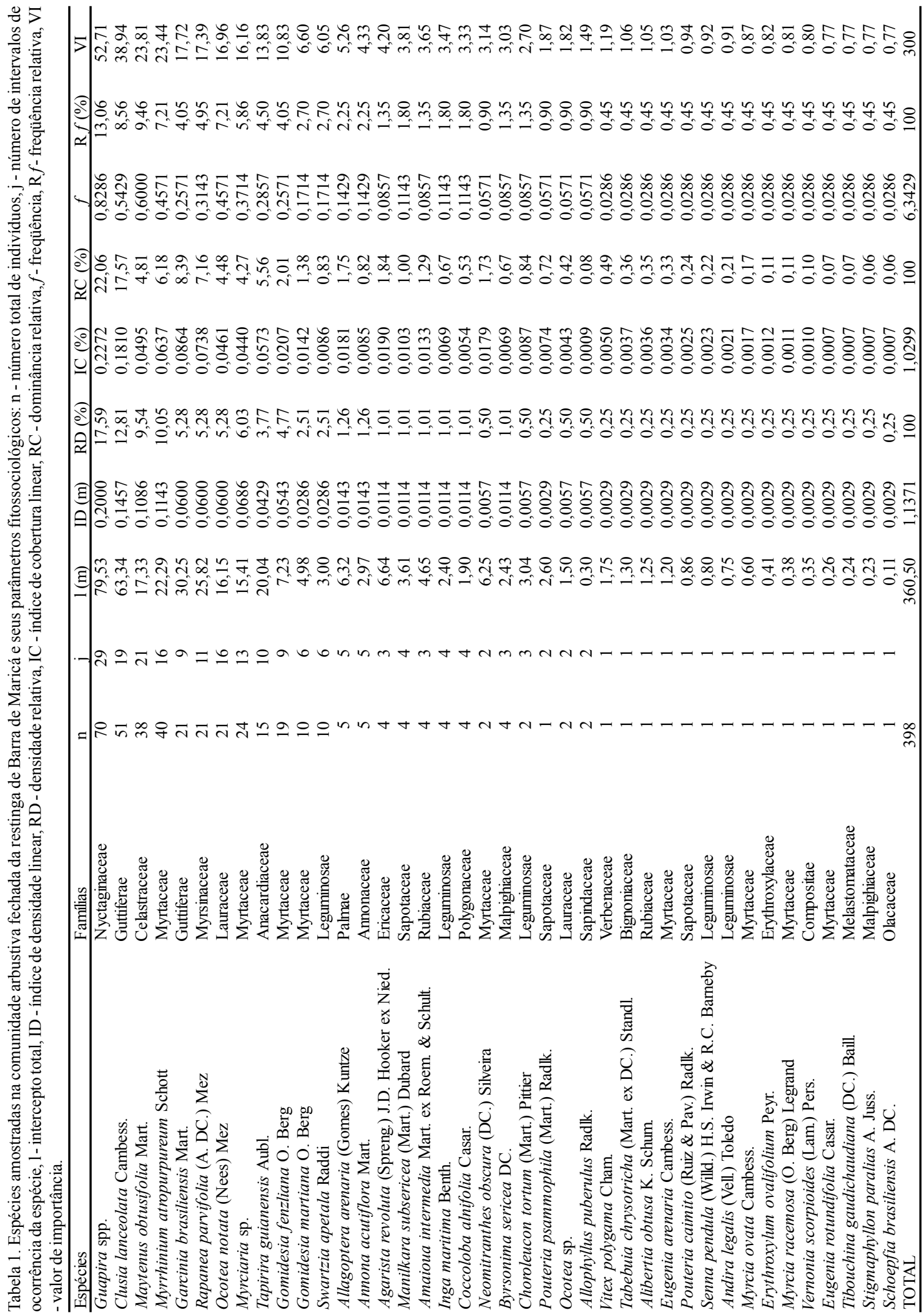


arbustivas nas restingas de Maricá (Silva 1991) e Carapebus (Montezuma 1997, Zaluar 1997), o número de indivíduos desta família tende a ser alto. Este fato também foi constatado em formações florestais de restinga nos estados do Pará (Bastos1996), Rio Grande do Norte (Trindade 1991), Espírito Santo (Fabris 1995), São Paulo (Sugiyama \& Mantovani 1993) e Paraná (Silva et al. 1993).

$\mathrm{Na}$ área em estudo, Leguminosae mostrou-se importante na composição florística, porém, sua representatividade na estrutura da comunidade arbustiva não foi comprovada, ao contrário do que foi verificado na floresta de restinga da Reserva Ecológica Estadual de Jacarepiá (município de Saquarema, RJ), onde Leguminosae apresenta os maiores números de espécies, indivíduos e valores de VI (C.F.C. de Sá \& D.S.D. Araujo, dados não publicados). Se considerado seu VI na comunidade estudada em Maricá, este se encontra em posição inferior ao obtido por Sá (1996) no Estado do Rio de Janeiro, assim como, em estudos desenvolvidos em outros estados (Trindade 1991, Sugiyama \& Mantovani 1993, Bastos 1996).

A tabela 1 apresenta os parâmetros fitossociológicos calculados para os 40 táxons (contando as três espécies de Guapira como um único táxon), listados em ordem decrescente de VI. Os elevados valores de Guapira spp., encontrados para todos os parâmetros, ocorreram em função da inclusão neste táxon de Guapira pernambucensis, Guapira opposita e Guapira sp., que são as existentes na área.

As 12 espécies com maiores VIs representam $73,6 \%$ do total deste parâmetro. Comparando-se este resultado com o obtido por Silva (1991) na comunidade de moitas adjacente à área estudada, verificou-se que 14 espécies totalizam $74 \%$ do VI. $\mathrm{Na}$ restinga de Carapebus, em uma comunidade fisionomicamente semelhante, 10 espécies totalizam cerca de $75 \%$ do VI (Zaluar 1997). Nas formações arbóreas de restingas, observou-se uma variação entre 14 e 22 espécies, somando a mesma percentagem de VI (Trindade 1991, Silva et al. 1993, Bastos 1996).

Portanto, é possível sugerir que, nas restingas, as formações florestais possuem melhor eqüitabilidade e, conseqüentemente, maior diversidade. Tratando-se do grupo de espécies dominantes e não do total de espécies, a utilização de métodos diferentes tem menor influência na variação encontrada.
A importância de Clusia lanceolata deve-se à elevada dominância. Esta parece ser uma característica do gênero Clusia que, em formações florestais ou arbustivas descontínuas de restinga, tende a ocupar as primeiras posições com relação a este parâmetro, independente do método utilizado (Silva et al. 1993, Sugiyama \& Mantovani 1993, Fabris 1995, Montezuma 1997, Zaluar 1997).

Com exceção de $C$. lanceolata, as espécies com maior número de indivíduos tiveram baixos valores para dominância, o que pode ser explicado pela concentração de indivíduos nas classes com valores mais baixos de diâmetro de copa (figura 3). Portanto, a estrutura da comunidade baseia-se num elevado número de indivíduos com copas contíguas ou mesmo sobrepostas, refletindo a realidade da fisionomia densa e contínua da comunidade.

Considerando os parâmetros analisados, destacam-se, ainda, Maytenus obtusifolia e Myrrhinium atropurpureum (tabela 1). M. obtusifolia é abundante nas restingas do Rio de Janeiro; inclusive, na porção florestal do Complexo Lagunar Grussai/Iquipari (RJ), esta apresenta maior VI (Assumpção \& Nascimento 2000). Entretanto, nas restingas de Ericaceae e de Clusia em Carapebus (Montezuma 1997, Zaluar 1997), possui menor importância.

Com relação a Myrrhinium atropurpureum, a variedade típica, aqui amostrada, é endêmica às restingas do Estado do Rio de Janeiro (Landrum 1986) entre Marambaia e Barra de São João (Araujo 2000), sendo mencionada, em estudos estruturais, apenas por Silva (1991) e Menezes \& Araujo (1999), ocupando posições inferiores para os parâmetros considerados.

As espécies raras representam 38\% do total de espécies amostradas, superior aos índices registrados em estudos realizados em comunidades arbustivas de restinga, contínuas e descontínuas (tabela 2).

Das 16 espécies consideradas raras na amostra, seis possuem distribuição ampla no Brasil, mas são representadas por poucos indivíduos nas restingas fluminenses: Tabebuia chrysotricha, Schoepfia brasiliensis, Senna pendula, Andira legalis, Vitex polygama e Pouteria caimito. Três espécies ocorrem com maior abundância em outras formações vegetais dos cordões arenosos (Eugenia rotundifolia, Pouteria psammofila e Stigmaphyllon paralias). Tibouchina gaudichaudiana e Vernonia scorpioides ocorrem com maior freqüência na região de transição 
brejo-cordão. Alibertia obtusa aparentemente está restrita às restingas de Maricá, Cabo Frio e Marambaia, sendo mais comum em áreas de dunas (Araujo 2000).

Myrcia racemosa, Myrcia ovata e Eugenia arenaria (Myrtaceae) não podem ser incluídas junto com as demais, pois a falta de identificação taxonômica precisa, relativa a material depositado em herbário, dificulta a determinação da distribuição dessas espécies nas restingas do Estado do Rio de Janeiro.

Erythroxylum ovalifolium possui ampla distribuição nas restingas fluminenses, apresenta elevado VI na comunidade adjacente de moitas (Silva 1991) e ocorre ao longo de todo o processo de evolução da vegetação estudada por Ribas (1992), também, na restinga de Maricá. A raridade desta espécie na formação arbustiva fechada em estudo indica que provavelmente ela é característica de formações descontínuas, organizadas em moitas.

A divisão da comunidade estudada por uma estrada de terra, a proximidade de uma das subáreas de um morrote de argila (Morro do Mololô) e, principalmente, a ocorrência de espécies exclusivas propiciaram a comparação entre as duas subáreas com a utilização do índice de Sörensen, um dos mais usados como medida de $\beta$ diversidade entre pares de localidades (Magurran 1988). Análises qualitativas de similaridade (presença/ausência de espécies) são geralmente insatisfatórias pois não levam em consideração a abundância de indivíduos em cada espécie, e este parâmetro, freqüentemente, é fundamental na determinação do grau de similaridade entre localidades, independentemente de uma elevada semelhança florística. Portanto, foi utilizado, também, o índice Sörensen quantitativo. Quando comparadas as subáreas I e II, o índice de Sörensen $\left(C_{S}\right)$ foi de 0,62 e o Sörensen quantitativo $\left(\mathrm{C}_{\mathrm{N}}\right)$ de 0,56. Dado este grau de similaridade e levando-se em conta que as duas subáreas são fisionomicamente iguais, partiu-se do princípio que estas compõem uma única comunidade.
Além disso, das 14 espécies exclusivas para a subárea I (Garcinia brasiliensis, Swartzia apetala, Alibertia obtusa, Amaioua intermedia, Andira legalis, Myrcia ovata, Ocotea sp., Pouteria caimito, Pouteria psammofila, Schoepfia brasiliensis, Tabebuia chrysotricha, Tibouchina gaudichaudiana, Vernonia scorpioides e Vitex polygama) apenas as duas primeiras apresentaram abundância relativamente elevada. Oito espécies ocorreram somente na subárea II (Erythroxylum ovalifolium, Eugenia arenaria, Eugenia rotundifolia, Agarista revoluta, Myrcia racemosa, Choroleucon tortum, Senna pendula e Stigmaphyllon paralias), nenhuma apresentando elevado número de indivíduos.

A similaridade florística entre a comunidade em estudo e a de moitas adjacente (Silva 1991) é $\mathrm{C}_{\mathrm{S}}=$ 0,63 . Estas são fisionomicamente distintas, sendo que, na formação aberta, as moitas ocupam $28 \%$ da área, intercaladas por espaços com baixa cobertura vegetal, enquanto que a comunidade aqui estudada apresenta elevada cobertura vegetal, ocupando mais de $90 \%$ da área. Levando em consideração a abundância das espécies, a similaridade entre as áreas diminui $\left(\mathrm{C}_{\mathrm{N}}=0,46\right)$, comprovando que, para a diferenciação de comunidades vegetais, os dados estruturais devem ser levados em consideração (Braun-Blanquet 1979).

$\mathrm{Na}$ mesma restinga, outra comunidade descontínua foi analisada por Ribas (1992), porém em um trecho localizado entre cordões, não havendo formação de brejo devido ao nível topográfico um pouco mais elevado. A similaridade entre a comunidade em estudo e a de Ribas (1992) é $\mathrm{C}_{\mathrm{S}}=$ 0,35, enquanto que entre a de Ribas (1992) e a analisada por Silva (1991) é $\mathrm{C}_{\mathrm{S}}=0,45$, caracterizandoas como três comunidades distintas.

O índice de diversidade de Shannon para a comunidade analisada foi de $\mathrm{H}^{\prime}=2,84$ nats/ind., muito próximo ao encontrado por outros autores em diferentes trechos de restinga, considerando

Tabela 2. Comparação de riqueza e diversidade de espécies em 5 comunidades de restinga.

\begin{tabular}{|c|c|c|c|c|c|}
\hline & Este trabalho & Fabris et al. (1990) & Silva (1991) & Montezuma (1997) & Zaluar (1997) \\
\hline Tipo de comunidade & Arbustiva fechada & $\begin{array}{l}\text { Arbustiva fechada } \\
\text { pós-praia }\end{array}$ & Arbustiva aberta & Arbustiva aberta & Arbustiva aberta \\
\hline Método & Intercepção por linha & Intercepção por linha & Intercepção por linha & Transecto & Intercepção por linha \\
\hline Número de espécies & 42 & 39 & 41 & 43 & 35 \\
\hline $\mathrm{H}^{\prime}=$ nats/ind & 2,84 & 2,93 & 2,82 & 2,63 & 2,92 \\
\hline Índice de espécies raras & $38 \%$ & $15 \%$ & $15 \%$ & $19 \%$ & $20 \%$ \\
\hline
\end{tabular}


vegetações arbustivas contínuas ou descontínuas (tabela 2). Se comparado com formações florestais de restinga, este valor fica abaixo dos encontrados por Trindade (1991), Silva et al. (1993) e Fabris (1995), que variaram entre 3 e 3,7 nats/ind.

No estado do Rio de Janeiro, as comunidades arbustivas de restinga têm sido classificadas, a partir de suas características fisionômicas, em formações abertas ou descontínuas (de Clusia, de Ericaceae, de Palmae) e fechadas ou contínuas (de Myrtaceae e pós-praia) (Araujo \& Henriques 1984, Araujo 1992).

Apesar do elevado valor de dominância de Guttiferae, representada por Clusia lanceolata e Garcinia brasiliensis, a comunidade analisada não se enquadra na classificação "scrub" de Clusia, de Araujo \& Henriques (1984), por apresentar cobertura contínua. Além disso, uma comparação entre a lista de espécies das restingas do Rio de Janeiro (Araujo 2000) com as espécies amostradas, revela que do total destas, nenhuma é exclusiva da formação aberta de Clusia enquanto $43 \%$ ocorrem exclusivamente na formação fechada de Myrtaceae; $48 \%$ ocorrem nas duas comunidades.

Araujo \& Henriques (1984) caracterizaram a comunidade arbustiva fechada de Myrtaceae como uma formação de dossel contínuo, com porte de até cinco metros e elevado número de espécies de Myrtaceae, além de outros atributos florísticos. A comunidade vegetal analisada em Barra de Maricá enquadra-se nessa descrição em termos físionômicos pois é uma vegetação contínua de baixo porte e florísticamente porque apresenta riqueza em espécies de Myrtaceae. Além disso, os resultados do trabalho em pauta demonstram que o valor de importância de Myrtaceae é alto, baseado principalmente no grande número de indivíduos. Embora outras duas famílias, Nyctaginaceae e Guttiferae, também possuam elevado número de indivíduos, porém baixo número de espécies, e Leguminosae apresente riqueza de espécies mas baixo número de indivíduos, optou-se por manter a designação de Araujo \& Henriques (1984) para esta comunidade.

A nomenclatura para comunidades de restinga ainda é uma questão em aberto, sendo que futuras análises dos trabalhos já realizados em Maricá, juntamente com estudos em andamento em outras restingas, poderão auxiliar na elaboração de uma classificação mais abrangente.
Agradecimentos - Ao Conselho Nacional de Desenvolvimento Científico e Tecnológico (CNPq) pelas bolsas de Iniciação Científica e Aperfeiçoamento Científico concedidas a primeira autora e à Fundação de Amparo à Pesquisa do Rio de Janeiro (FAPERJ) pelo auxílio (Proc. 170.694/88) recebido para realização deste trabalho

\section{Referências bibliográficas}

ARAUJO, D.S.D. 1992. Vegetation types of sandy coastal plains of tropical Brazil: a first approximation. In Coastal plant communities of Latin America (U. Seeliger, ed.). Academic Press, New York, p.337-347.

ARAUJO, D.S.D. 2000. Análise florística e fitogeográfica das restingas do Estado do Rio de Janeiro. Tese de doutorado, Universidade Federal do Rio de Janeiro, Rio de Janeiro.

ARAUJO, D.S.D. \& HENRIQUES, R.B.P. 1984. Análise florística das restingas do Estado do Rio de Janeiro. In Restingas: origem, estrutura, processos (L.D. Lacerda, D.S.D. Araujo, R. Cerqueira \& B. Turcq, orgs.). Universidade Federal Fluminense/ CEUFF, Niterói, p.159 $-193$.

ARAUJO, D.S.D. \& PEIXOTO, A.L. 1977. Renovação da comunidade vegetal de restinga após queimada. In Anais do XXVII Congresso Nacional de Botânica. Academia Brasileira de Ciências, Rio de Janeiro, p.1-18.

ASSUMPÇÃO, J. \& NASCIMENTO, M.T. 1998. Fitofisionomia de uma restinga no extremo norte do litoral fluminense: um novo elemento no mosaico? In Anais do IV Simpósio de Ecossistemas Brasileiros (S. Watanabe, coord.). ACIESP, São Paulo, p.158-164.

ASSUMPÇÃO, J. \& NASCIMENTO, M.T. 2000. Estrutura e composição florística de quatro formações vegetais de restinga no complexo lagunar de Grussaí/Iquipari, São João da Barra, RJ, Brasil. Acta Botanica Brasilica 14:301315.

BASTOS, M.N.C. 1996. Caracterização das formações vegetais da restinga da Princesa, Ilha de Algodoal-Pará. Tese de doutorado, Universidade Federal do Pará/Museu Paraense Emílio Goeldi, Belém.

BRAUN-BLANQUET, J.K. 1979. Fitosociologia: Bases para el estudio de las comunidades vegetales. H. Blume Ediciones, Madrid.

BROWER, J.E. \& ZAR, J.H. 1984. Field \& laboratory methods for general ecology. 2 ed., Wm. Brown Co., Dubuque.

BRUMMITT, R.K. \& POWELL, C.E. 1992. Authors of plant names. Royal Botanical Gardens, Kew.

ENGLER, H.G.A. 1964. Syllabus der Pflanzenfamilien. (H. Melchior, ed.). Nikolassee, Gebrüder Borntraeger, Berlin, 12 Aufl. v.2. 666 p.

FABRIS, L.C. 1995. Composição florística e fitossociológica de uma faixa de floresta arenosa litorânea do Parque Estadual de Setiba, Município de Guarapari, ES. Dissertação de mestrado, Universidade Estadual Paulista, Rio Claro.

FABRIS, L.C., PEREIRA, O.J. \& ARAUJO, D.S.D. 1990. Análise fitossociológica na formação pós-praia da restinga de Setiba, Guarapari, ES. In Anais do II Simpósio de Ecossistemas da Costa Sul - Sudeste Brasileira (S. Watanabe, coord.). ACIESP, São Paulo, p.455-466. 
GARCIA, G.J. \& PIEDADE, G.C.R. 1987. Topografia aplicada às ciências agrárias. 5 ed. Editora Nobel, São Paulo.

HENRIQUES, R.P.B., ARAUJO, D.S.D. \& HAY, J.D. 1986. Descrição e classificação dos tipos de vegetação da restinga de Carapebus, Rio de Janeiro. Revista Brasileira de Botânica 9:173-189.

LANDRUM, L.R. 1986. Campomanesia, Pimenta, Blepharocalyx, Legrandia, Acca, Myrrhinium e Luma (Myrtaceae). Flora Neotropica - Monograph 45:1179.

MAGURRAN, A.E. 1988. Ecological diversity and its measurement. Princeton University Press, Princeton.

MARTINS, F.R. 1991. Estrutura de uma floresta mesófila. Editora da Universidade Estadual de Campinas, Campinas.

MENEZES, L.F.T. \& ARAUJO, D.S.D. 1999. Estrutura de duas formações vegetais do cordão externo da restinga de Marambaia, RJ. Acta Botanica Brasilica 13:115-236.

MONTEZUMA, R.C.M. 1997. Estrutura da vegetação de uma restinga de Ericaceae no Município de Carapebus RJ. Dissertação de mestrado, Universidade Federal Rio de Janeiro, Rio de Janeiro.

MUELLER-DOMBOIS, D. \& ELLENBERG, H. 1974. Aims and methods of vegetation ecology. John Wiley \& Sons, New York.

NIMER, E. 1972. Climatologia da região Sudeste do Brasil. Revista Brasileira de Geografia 34:3-48.

PERRIN, P. 1984. Evolução da costa fluminense entre as pontas de Itacoatiara e Negra: preenchimentos e restingas. In Restingas: origem, estrutura, processos (L.D. Lacerda, D.S.D. Araujo, R. Cerqueira \& B. Turcq, orgs.). Universidade Federal Fluminense/ CEUFF, Niterói, p.6573.
RIBAS, L.A. 1992. Análise da estrutura e composição específica das comunidades vegetais de moitas de restinga, em Maricá - RJ. Dissertação de mestrado, Universidade de Brasília, Brasília.

RIBAS, L.A., HAY, J.D. \& CALDAS-SOARES, J.F. 1993. Moitas de restinga: ilhas ecológicas? In Anais do III Simpósio de Ecossistemas da Costa Brasileira (S. Watanabe, coord.). ACIESP, São Paulo, p.79-88.

SÁ, C.F.C. 1996. Regeneração em área de floresta de restinga da Reserva Ecológica Estadual de Jacarepiá, Saquarema RJ. Arquivos do Jardim Botânico do Rio de Janeiro 34:177-192.

SILVA, M.B.R. 1991. Fitossociologia da vegetação lenhosa de restinga em Maricá, Rio de Janeiro. Dissertação de mestrado, Universidade Federal do Rio de Janeiro, Rio de Janeiro.

SILVA, S.M., BRITEZ, R.M., SOUZA, W. S. \& JOLY, C.A. 1993. Fitossociologia do componente arbóreo da floresta de restinga da Ilha do Mel, Paranaguá, PR. In Anais do III Simpósio de Ecossistemas da Costa Brasileira (S. Watanabe, coord.). ACIESP, São Paulo, p.33-48.

SUGIYAMA, M. \& MANTOVANI, W. 1993. Fitossociologia de um trecho de mata de restinga na Ilha do Cardoso, SP. In Anais do III Simpósio de Ecossistemas da Costa Brasileira (S. Watanabe, coord.). ACIESP, São Paulo, p.4966.

TRINDADE, A. 1991. Estudo florístico e fitossociológico do estrato arbustivo-arbóreo de um trecho de floresta arenícola costeira do Parque Estadual das Dunas - Natal RN. Dissertação de mestrado, Universidade Federal Rural de Pernambuco, Recife.

ZALUAR, H.L.T. 1997. Espécies focais e a formação de moitas na restinga aberta de Clusia, Carapebus, RJ. Dissertação de mestrado, Universidade Federal do Rio de Janeiro, Rio de Janeiro. 
